\title{
HEAT TREATING CORUNDUM: THE BANGKOK OPERATION
}

By Jack S. D. Abraham

Following up on Nassau's 1981 article on the technical aspects of heat treating ruby and sapphire, the author reports his personal observations of the actual heat treatment process in Bangkok. He discusses the potential effects that this process can have on a stone-both positive and negative-and emphasizes the importance of the natural make-up of the stone itself to the success of heat treatment.

\section{ABOUT THE AUTHOR}

Mr. Abraham is president of Precious Gem Resources, Inc., New York, New York.

Acknowledgment: The author would like to thank all his friends and associates in Bangkok for being so candid and helping to enlighten the public on this subject.

01982 Precious Gem Resources, Inc.
A Bangkok gem dealer buys a $10+$-ct ruby for a sixfigure sum and heats it hoping to improve its color and value. After one heating, the stone dulls and cannot be sold for half of its original price. But a few tries later the stone is so improved that a major European dealer buys it for almost five times the original amountknowing that it has been heat treated.

Another Thai dealer pays a large sum for a 600 -ct piece of sapphire rough. He then cuts it into four sections and heats each. For the largest piece, which is over $100 \mathrm{ct}$, he receives $20 \%$ more than he paid for the entire original stone-again from a buyer who knows the stone is heated.

A third dealer, however, heats a sapphire for which he has paid a six-figure sum but instead of enhancing the color, the treatment causes the stone to break into several pieces. It is now worth a fraction of its original price.

Such incidents suggest that the heating of ruby and sapphire has become a fully accepted, if very risky, fact of life in the Far East. It is generally acknowledged in Bangkok that over $95 \%$ of the rubies and sapphires exported from the Far East have been subjected to heat treatment (figure 1). For a combination of reasons, including increased demand for corundum gems and the inadequacy of traditional sources, ruby and sapphire dealers worldwide are now dependent on heat treatment to generate meaningful market supplies.

This surge in interest in the heat treatment of corundum has led to a number of articles discussing manners and methods of treatment as well as the detection of treated vs. nontreated sapphire by the gemologist (Nassau, 1981; Crowningshield and Nassau, 1981). To date, however, very little has been published regarding the actual treatment of these stones in Bangkok and relating some of the practical aspects of the treatment process. The purpose of this article is to fill this void. 
Figure 1. This 80-ct blue sapphire from Sri Lanka and the five Thai rubies

(averaging $3.2 \mathrm{ct}$ each) that surround it are representative of the stones heat treated in Bangkok in recent years.

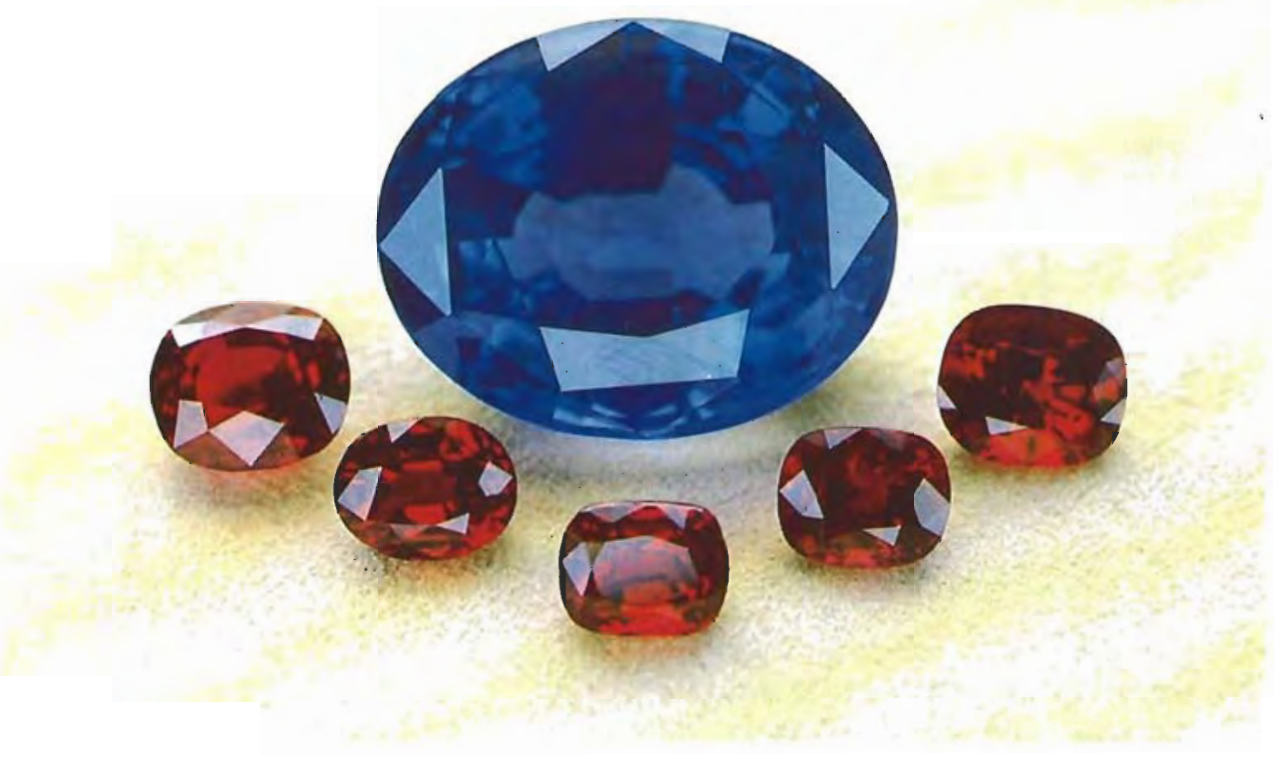

In the course of three recent visits (the last of which was in Spring 1982), the author explored this subject with friends and associates in Bangkok who are connoisseurs of the art of heat treating corundum, a secret that is very well guarded. During these visits, the author was able to study several Bangkok treatment operations firsthand and had detailed discussions about the processes with several leading dealers. These experiences form the basis of this article and should serve to augment the previous, more detailed and technical papers on the heat treatment of corundum cited above. It is important to note that Bangkok is not the only center for heat treating corundum, inasmuch as Sri Lanka, Australia, and Hong Kong have treatment operations as well. This article will deal only with the author's observations in Bangkok, however, and only with those stones that are heated to duplicate processes that could occur in nature.

\section{THE OBJECTIVES OF HEAT TREATMENT}

There are historical references in the literature that discuss the heat treatment of corundum from a purely scientific point of view (Mawe, 1813; King, 1870; Bauer and Spencer, 1904; Church, 1905). It is questionable, though, whether the treatment of sapphires was known to the commercial world prior to a few years ago, when gem dealers learned that they not only could enhance the existing color of some sapphires, but also could transform near-colorless sapphire with inherent latent qualities into fine fancy-colored stones, including yellow and green as well as blue. More recently, they found that excessively dark blue material could be lightened through heat treatment. They also found that some rubies could be improved with heating.

It soon became evident that heating could also result in cracked or shattered stones, or in the dulling of color or other damage. Furthermore, because color in a stone depends on the presence of trace amounts of certain elements (e.g., iron and titanium), the heating process will do absolutely nothing to improve color if these elements are absent from the original material.

Often, the heating of sapphire induces as much as an $80 \%$ to $90 \%$ color change, from grayish white or milky to various shades of blue. But all types of sapphire, from chalk white to ink black, are sent to the ovens. The specific objectives of heat treatment vary according to the quality of the sapphire being treated and the country of its origin (Sri Lanka, Thailand, Cambodia, Burma, Kashmir, or Australia). In general, it is easier to deepen the color of a stone than to lighten it. Specifically, a $70 \%$ color change from light blue to deep blue is less difficult to attain than a $10 \%$ reduction in color in an overly dark blue stone. This fact explains why some light, near-colorless pieces of Sri Lankan rough may sell for several times more than most deep blue Australian rough. In fact, the most desirable whitish-blue Sri Lankan rough commands prices comparable to those paid for blue rough five years ago. But reducing color, 
as in Australian stones, and darkening color, as in Sri Lankan stones, is not all that heating does. The process is of ten used to reduce and even eliminate "silk and asterism" in Burmese sapphires and, at the same time, enhance their color (Nassau, 1981).

Likewise, for ruby, heating is done to eliminate silk, to reduce secondary colors, and to increase the purity of the primary red. A mere 5\% increase in red can mask unappealing secondary colors by the same amount. And a decrease, say, in purple by just $5 \%$ can mean a dramatic increase in quality.

It must be emphasized that the heat-treatment process described here is designed to duplicate heating processes that could occur in nature; it can only bring out latent inherent qualities in the stone. In the author's experience, there has been no loss of color over time in heat-treated blue Sri Lankan sapphires and in rubies. This process should not be confused with diffusion treatment, which provides a colored synthetic coating to a natural stone (Nassau, 1981); this coating may be removed in polishing. The proposed Federal Trade Commission guides for the jewelry'industry (submitted by the Jewelers Vigilance Committee on December 31, 1981) do not require disclosure of heat treatment if it is not detectable by a gemological laboratory, as is the case with most heattreated corundum. However, the use of a colored synthetic coating, as in diffusion treatment, must be made known to the buyer. Knowledgeable labs can readily detect diffusion treatment (again, see Nassau, 1981) and already disclose it on their gem identification reports.

\section{THE HEAT-TREATMENT OPERATION}

Heat treatment in Bangkok is becoming more sophisticated. The design of the ovens and kilns has improved and the use of natural gas, various petroleum derivatives, and in some cases electricity allows these ovens and kilns to reach higher temperatures than the heat sources used in earlier ovens. For the most part, sapphires-which require oxygen to produce a color change-are treated in open-fire kilns using coal, natural gas, or petroleum derivatives. Rubies are likely to be treated in more sophisticated electric ovens. With the exception of the electric ovens used for rubies, there is still no thermostatic control. This means that the operators must keep close and constant watch during the entire treatment operation, particularly since the successful heat treatment of corundum can require temperatures close to the melting point of the gem. The fire kilns are usually no more than oil drums that have been lined with bricks, clay, or concrete with a side door toward the bottom through which fuel is pumped (figure 2). The hollow center of the drum holds the crucible containing the gem rough. Loose bricks control the flow and direction of the fire to ensure that the crucible is totally engulfed in flame. In the case of charcoal-burning kilns, the crucible is surrounded by the charcoal itself.

Prior to heat treatment, the gem rough is cleaned and any heavily cracked or included portions are removed by trimming. These cracks and internal imperfections can affect the durability of the stone during heating and can of ten lead to breakage. Many of the gems are actually preformed during the trimming process. Following

Figure 2. The basic drum often used for heat treating corundum. The hole at the bottom may serve to accommodate the fuel source (e.g., gas or other petroleum derivalives) or as the access point to control the flames when charcoal or wood is used. Illustration by Susan Kingsbury.

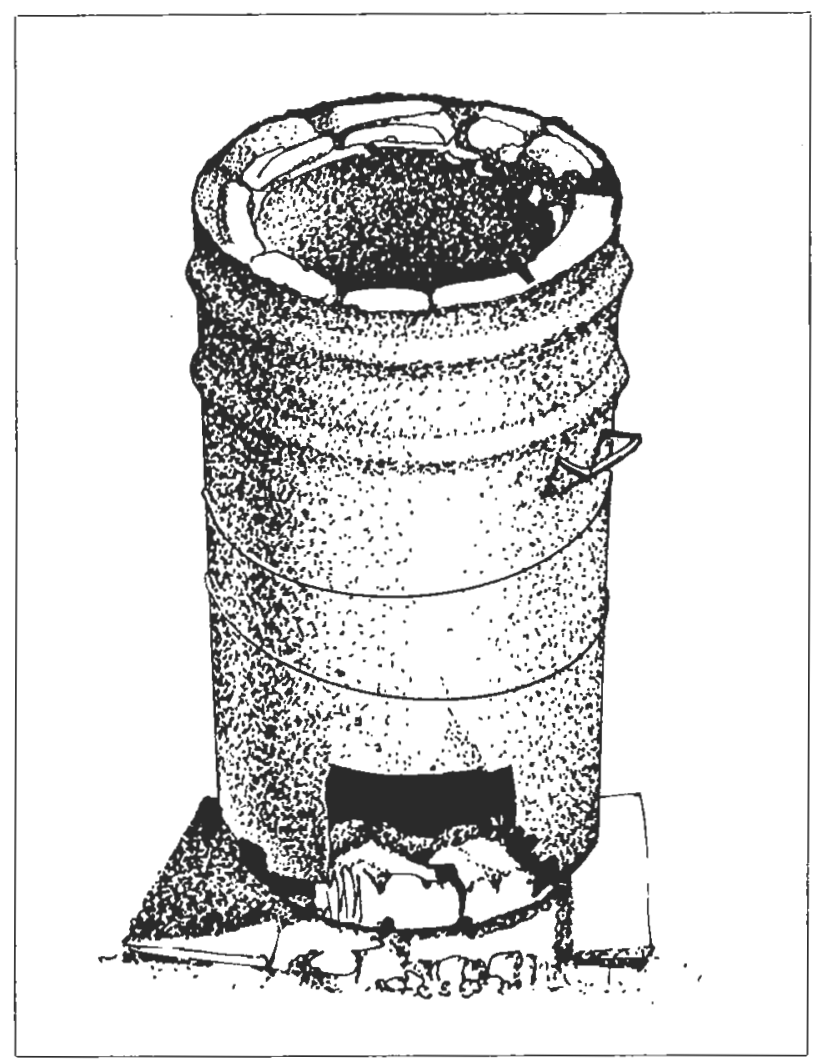




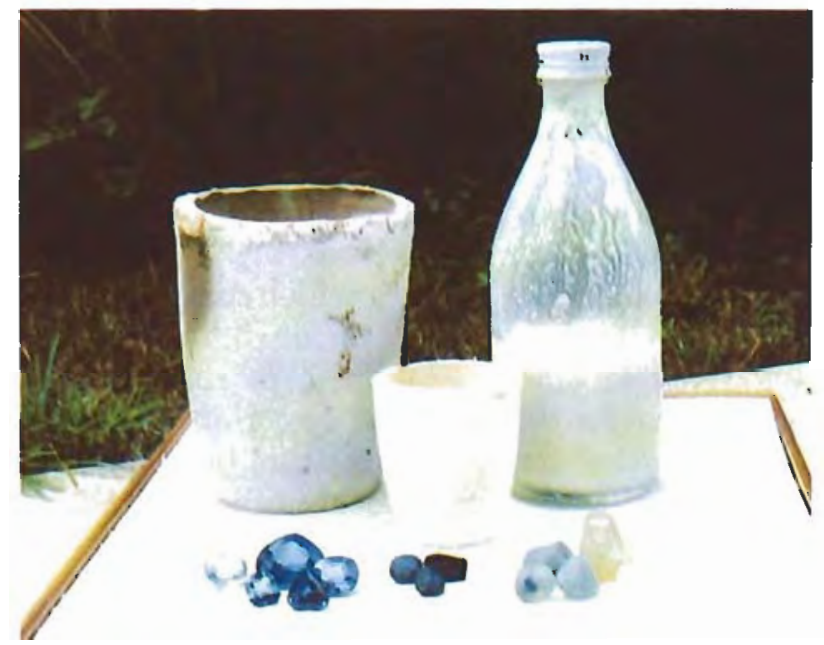

Figure 3. In some instances, the stones are coated with a borax-based solution before they are placed in the smaller crucible, which is then inserted into the larger crucible for heating. In other instances, the stones are left untouched and the small crucible itself is sealed with a borax solution. Some operators use no solution at all. The stones on the left have been heated to maximum color and recut. Those in the center have been heated and await recutting. Corundum slated for heating or reheating appears on the right.

cleaning and trimming, a few of the operators soak their stones in a borax-based solution /which varies according to the person who controls the operation) that is believed to form a "protective shell" on the stone to prevent damage (figure 3). The stones are then placed in ceramic crucibles and put into the kiln or oven, where they are heated up to $1600^{\circ} \mathrm{C}$ and maintained at that temperature for 24 hours or longer for sapphires and four to eight hours for rubies. Occasionally, higher temperatures are used, depending on the character of the stones, the oven used, and the skill of the operator. When the heating process is completed, the temperature is gradually reduced or the kiln is shut off and the gems left to cool slowly. This heating procedure may be repeated several times on a given stone until the stone attains what the operator feels is its best potential color and appearance; some stones are heated every time they change ownership. This, of course, can be very risky and improper heating may result in the shattering, cracking, dulling, overdarken-

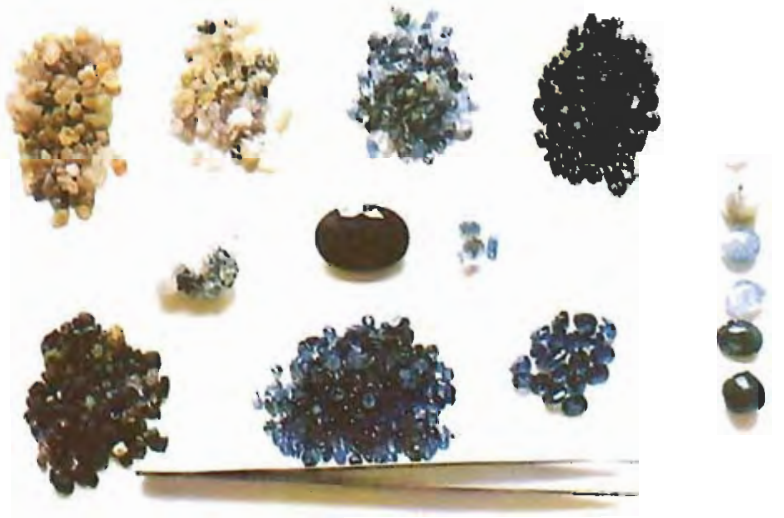

Figure 4. These groups illustrate the various results of heat treatment. It is evident that many of these stones lack the natural elements needed to attain good color. Note especially the mass of melted corundum to the left of the large blue sapphire in the center row.

ing, or even melting of a stone (figure 4). One can only imagine the great sums of money that are lost annually because dealers push their luck and their stones to the breaking point or misjudge color possibilities.

The heat treatment of corundum is as much an art as a science. The practitioners of this art, in Bangkok at least, all follow different rules, procedures, and formulas. These variations in technology and technique often make the difference between success and failure. For this reason, details of successful procedures remain jealously guarded, the backbone of a fascinating industry.

\section{REFERENCES}

Bauer M., Spencer L.J. (1904) Precious Stones (translation of 1896 German text). Charles Griffin \& Co., Ltd., London, pp. 265, 266, and 282.

Church A.H. (1905) Precious Stones. Wyman \& Sons, Ltd. London, p. 66.

Crowningshield R., Nassau K. (1981) The heat and diffusion treatment of natural and synthetic sapphires. Journal of Gemmology, Vol. 17, pp. 528-541.

King C.W. (1870) The Natural History of Gems, or Precious Stones. Bell and Daldy, London, pp. 225, 226, 251.

Mawe J. (1813) A Treatise on Diamonds and Precious Stones. Longman, Hurst, Rees, Orme and Brown, London, pp. 67 and 71 .

Nassau K. \{1981\} Heat treating ruby and sapphire: technical aspects. Gems $\Leftrightarrow$ Gemology, Vol. 17, pp. 121-131. 